\title{
Anti-Roll Bar Design and Material Selection for the Torsion Member for A Formula Student Vehicle
}

\author{
Dhruv Pathak, Biswajit Sahoo, Chandraneel Pal, Piyush Nanda \\ School of Mechanical Engineering, \\ Kalinga Institute of Industrial Technology, \\ Bhubaneshwar, India
}

\begin{abstract}
The following study will be dealing with the design procedure, constraints, and limitations that were dealt with during the design of the Anti-roll bar system of a formula student vehicle. Also, simulations with proper forces for torsion on the torsional member to select the best possible material for the torsion member was done.
\end{abstract}

\section{Keywords- FSAE, Anti-roll bar, Roll, Formula student}

\section{INTRODUCTION -}

Anti-roll bar sometime also known as a stabilizer bar or sway bar is used for the purpose of controlling the roll motion of the vehicle. It provides better stability during corning. Roll motion referred as to the motion in the lateral direction on the $\mathrm{Y}$-axis during which the vehicle rolls around the central axis of the vehicle.
Image
Courtesy-
RHD-JAPAN

Anti- Rollbar increases overall roll stiffness of the vehicle, thus providing a number of advantages to the vehicle and its performance.

One of the major advantages is that it provides better traction during cornering the vehicle.

\section{METHOD USED -}

The calculations were done in the following syntax -

RIDE RATES - ROLL ANALYSIS - ARB DIMENSIONS AND MATERIAL SELECTION

Ride rates were calculated by first determining the desired Natural frequencies of the front as well as rear but separately. These values were chosen using the general values which have validated after years of experimentation and observation.

Natural frequency for the front suspension $=2 \mathrm{~Hz}$

Natural frequency for the rear suspension $=2.5 \mathrm{~Hz}$

The reason behind aiming for higher natural frequency in the rear is to compensate for the response delay, since its always the front suspension which has to act first.

Then, the ride rates were calculated for the front and rear individually using the following expression-

$$
\mathrm{K}_{\mathrm{RF}}=\frac{4 \pi^{2} \omega_{\mathrm{F}}^{2}\left(\mathrm{~W}_{\mathrm{SF}} / 2\right)}{386.4}
$$

Here, $\mathrm{Krf}=$ Ride Rate

front $w F=$ Natural

Frequency Front

$\mathrm{Wsf}=$ Sprung mass

front

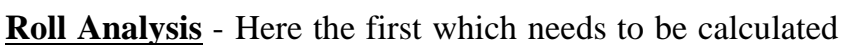
is the COG height of the sprung mass.

which can be calculated using the following expression Here, hs= sprung COG ht., $\mathrm{h}=\mathrm{COG}$ ht., Wuf=Unsprung

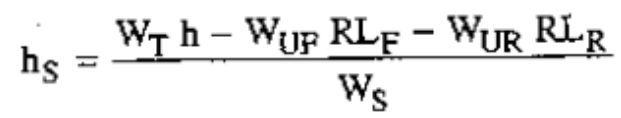

wt. Front,

$\mathrm{RLf}=$ Tire loaded radius(Static) front, Wur=Unsprung wt. Rear

RLr=Tire loaded radius(Static) Rear

Sprung Wt. distribution = Sprung wt front/Total sprung mass.

Rolling Moment (lever Arm) =

( Sprung mass cog ht.)-[Front Roll Centre ht+(Rear Roll Centre ht.-Front Roll Centre ht.)(1-sprung mass wt. distribution)]

Rolling moment per $\mathrm{g}$ lateral acceleration $=$

$$
\frac{\mathrm{M}_{\phi}}{\mathrm{A}_{\mathrm{y}}}=\frac{\mathrm{h}_{\mathrm{RM}} \mathrm{W}_{\mathrm{S}}}{12}
$$

Here, Hrm= Rolling moment (lever arm)

---- Calculated above

Now, dividing this value with the desired roll gradient will

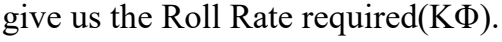

Roll gradient should be taken between 1.5 - 3deg/g for an fs vehicle.

Now calculate available Front spring roll rate by using the following expression - 


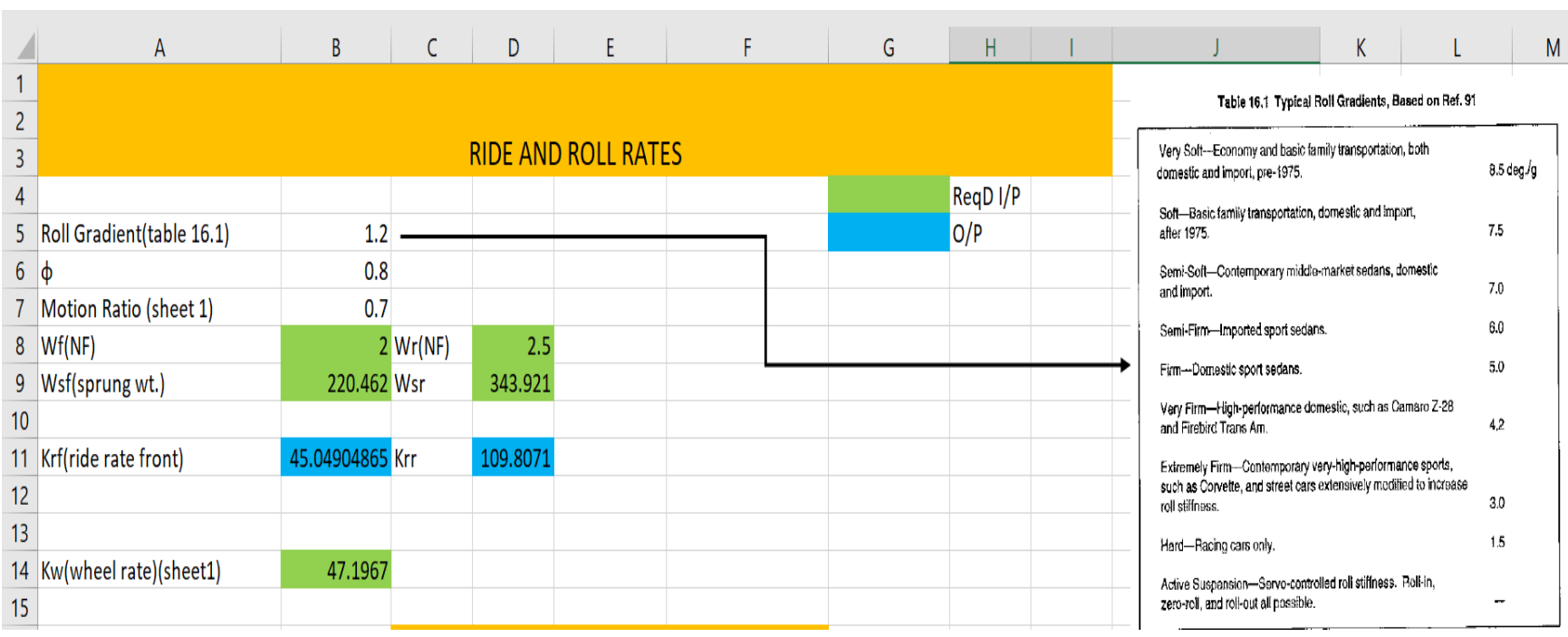

Here, $\mathrm{K} \Phi$ sf $=$ Front spring roll rate

$\mathrm{Krf}=$ Ride rate front (calculated during ride analysis)

$\mathrm{Tf}=$ Track width front

Similarly, by using adequate value, the available rear spring roll rate(KФsr) can be determined.

Adding both the front and rear roll rates will give us the total available roll rate.

So, arb must provide $=$ Required roll rate - available roll rate

Now, to size the front and rear bars, we need to calculate this requirement based on the weight distribution of the vehicle.
Multiply this with \%load transfer X 100 to get front/rear load transfer.

Front Roll Stiffness (Kфf) =

$$
\frac{F L T}{A_{y}}=\frac{12\left(\mathrm{~K}_{\phi F}\right) \phi}{T_{F}}+\frac{W_{S F} Z_{F}}{T_{F}}+\frac{W_{U F} R L_{F}}{T_{F}}
$$

Here, $\phi=$ Roll Gain ( 0.5 - 1 for non-aero fs vehicles)

From here, it can be calculated that the rear arb must provide

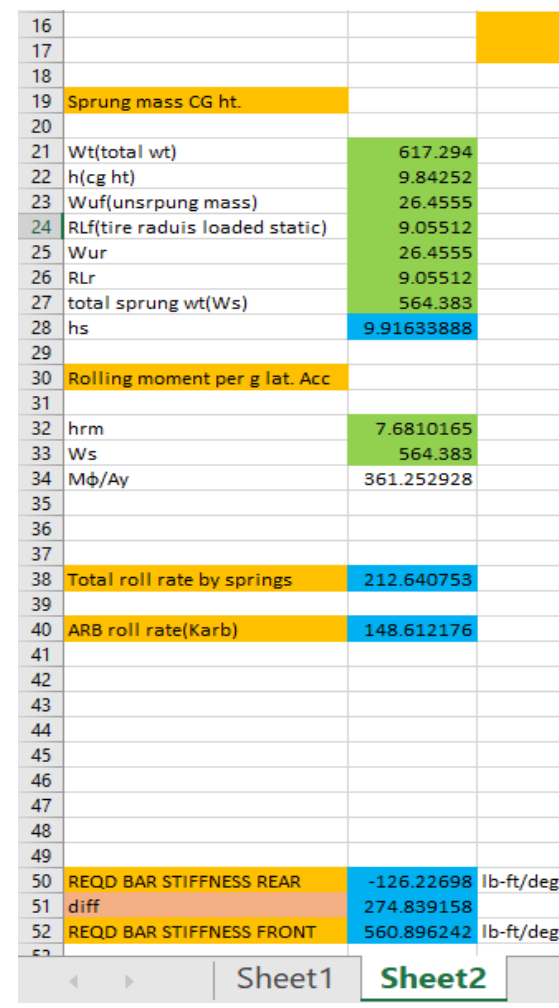

Here, TLT/Ay $=$ Total load transfer during lateral acceleration.

Tave $=$ Average of Front and Rear track width

\section{ROLL ANALYSIS}
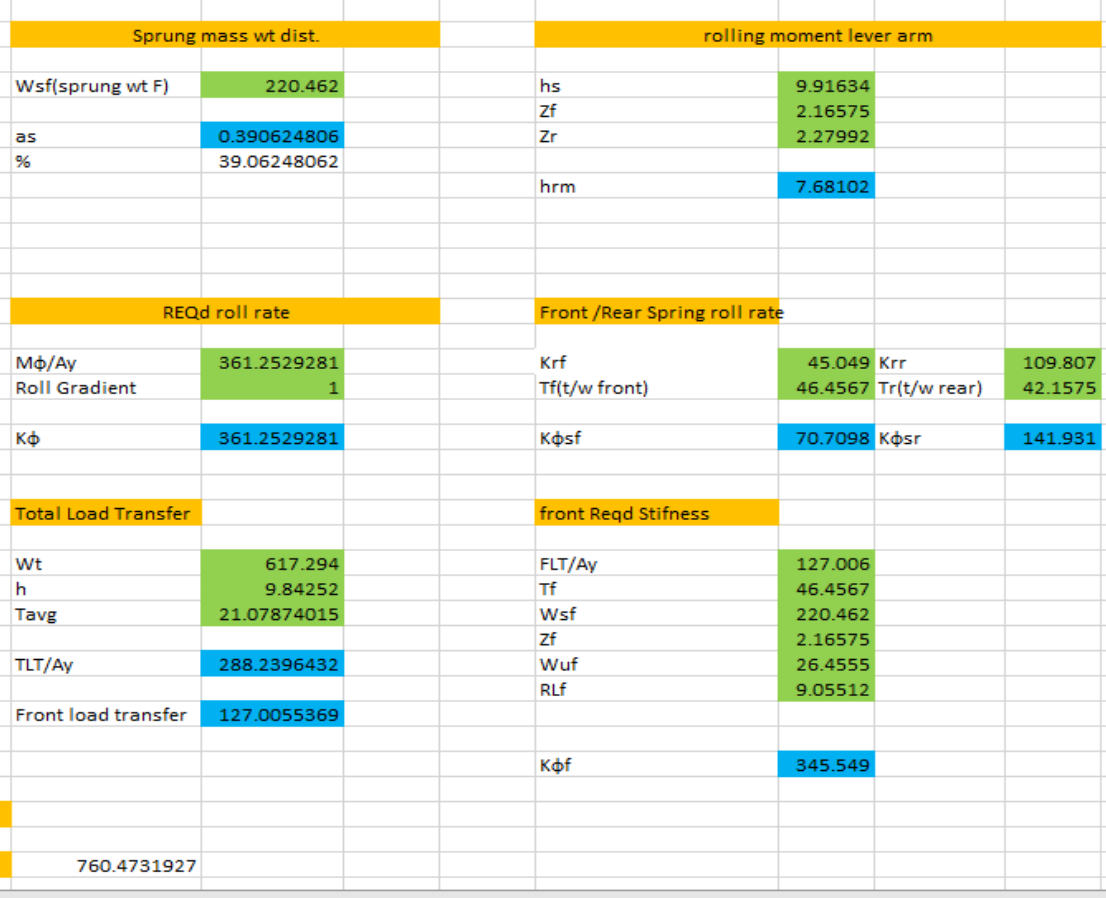

the difference between the total, rear, and that provided by the rear springs.

$\mathrm{K} \phi(\mathrm{arb}) \mathrm{rear}=\mathrm{K} \phi-\mathrm{K} \phi \mathrm{f}-\mathrm{K} \phi s \mathrm{r}$ 
Divide this by the Linkage ratio(rear) to get the final requirement.

For the front,

$\mathrm{K} \phi(\mathrm{arb})$ front $=(\mathrm{K} \phi f-\mathrm{K} \phi s f) /$ linkage ratio(front)

RESULTS AND DISCUSSION FOR THE METHOD

The whole calculation was done by preparing a spreadsheet to facilitate the calculations. For which the results are shown as followed -

It can be seen that the required stiffness for the rear comes out to be negative, which symbolizes that the rear suspension is stiff enough and does not require an arb setup.

\section{MATERIAL SELECTION}

The following materials were considered-

Mild steel - AISI 1020

$80 \mathrm{GPa}$ shear

modulus

Aluminum - AL-7075 T6

26.9 GPa shear

modulus

Magnesium alloy - AZ31B

17 GPa shear modulus

Although magnesium alloy provides great weight reduction advantage it is expensive and also for the same thickness, withstands lower stress than aluminum.

After running simulations aluminum was considered as the optimal choice as it provided enough durability, is

lightweight, and cheaper than magnesium alloy.

The size was determined by comparing the required area moment of inertial to the area moment of inertia of the arb system torsion bar with desired dimensions.

Required area moment of inertia $=[($ Required Roll stiffness $\mathrm{X}$ Length of tube)/Shear Modulus]

Area moment of inertia for cylindrical tube $=\left[\pi\left(D^{4}-\right.\right.$ $\left.\left.d^{4}\right)\right] / 32$

The following simulation was done by applying $650 \mathrm{~N}$ on both ends in torsion that sums up to $1300 \mathrm{~N}$ in total.

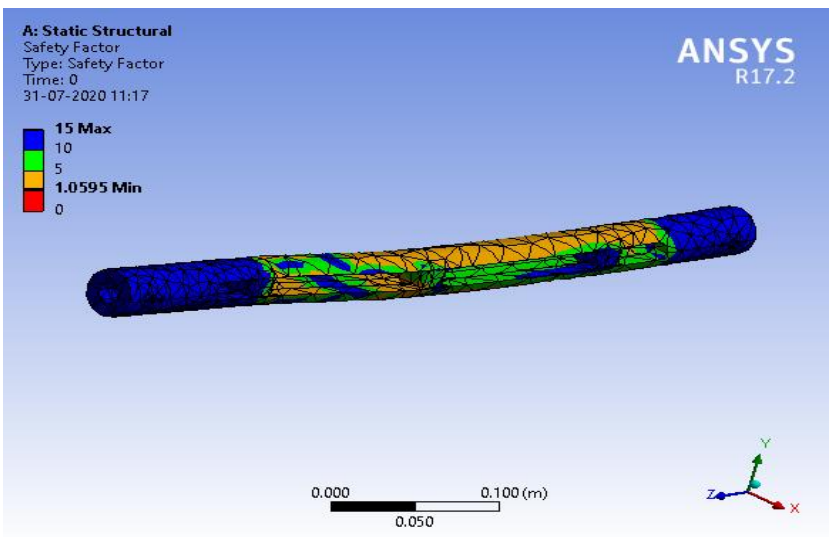

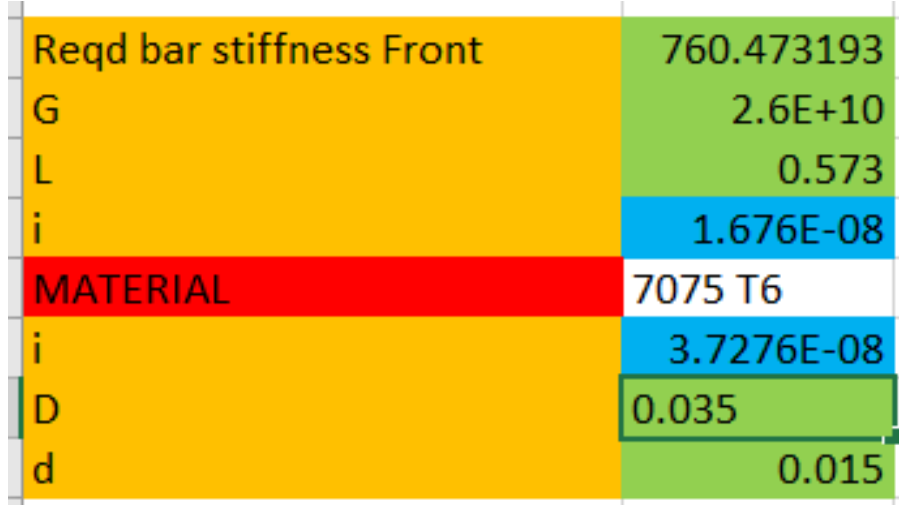

With dimensions $\mathrm{OD}=35 \mathrm{~mm}$

$\mathrm{ID}=15 \mathrm{~mm}$

\section{CONCLUSION -}

Anti-roll bar torsion member with outer diameter of $35 \mathrm{~mm}$ and inner diameter $15 \mathrm{~mm}$ was designed to provide roll stiffness of $760.4731927 \mathrm{Nm} / \mathrm{mm}$.

\section{ACKNOWLEDGMENT}

Biswajit Sahoo, School of mechanical engineering, Kalinga Institute of Industrial Technology

Chandraneel Pal, School of mechanical engineering,

Kalinga Institute of Industrial Technology

Piyush Nanda, School of mechanical engineering, Kalinga Institute of Industrial Technology

Softwares Used - CAD Modelling - Solidworks 2020 Simulation - Ansys R17.2

\section{REFERENCES}

Racecar vehicle dynamics, William F. Millikan; Douglas Millikan 